\title{
Heterogeneous formic acid production by hydrogenation of CO2 catalyzed by Irbpy embedded in polyphenylene porous organic polymers
}

Bennedsen, Niklas Rosendal; Christensen, David Benjamin; Mortensen, Rasmus Lykke; Wang, Bolun; Wang, Ryan; Kramer, Søren; Kegnæs, Søren

\section{Published in:}

ChemCatChem

Link to article, DOI:

$10.1002 /$ cctc. 202100002

Publication date:

2021

Document Version

Peer reviewed version

Link back to DTU Orbit

Citation (APA):

Bennedsen, N. R., Christensen, D. B., Mortensen, R. L., Wang, B., Wang, R., Kramer, S., \& Kegnæs, S. (2021). Heterogeneous formic acid production by hydrogenation of CO2 catalyzed by Irbpy embedded in polyphenylene porous organic polymers. ChemCatChem, 13(7), 1781-1786. https://doi.org/10.1002/cctc.202100002

\section{General rights}

Copyright and moral rights for the publications made accessible in the public portal are retained by the authors and/or other copyright owners and it is a condition of accessing publications that users recognise and abide by the legal requirements associated with these rights.

- Users may download and print one copy of any publication from the public portal for the purpose of private study or research.

- You may not further distribute the material or use it for any profit-making activity or commercial gain

- You may freely distribute the URL identifying the publication in the public portal 


\section{ChemCatChem}

The European Society Journal for Catalysis

\section{F. Chemistry Europe}

European Chemical Societies Publishing

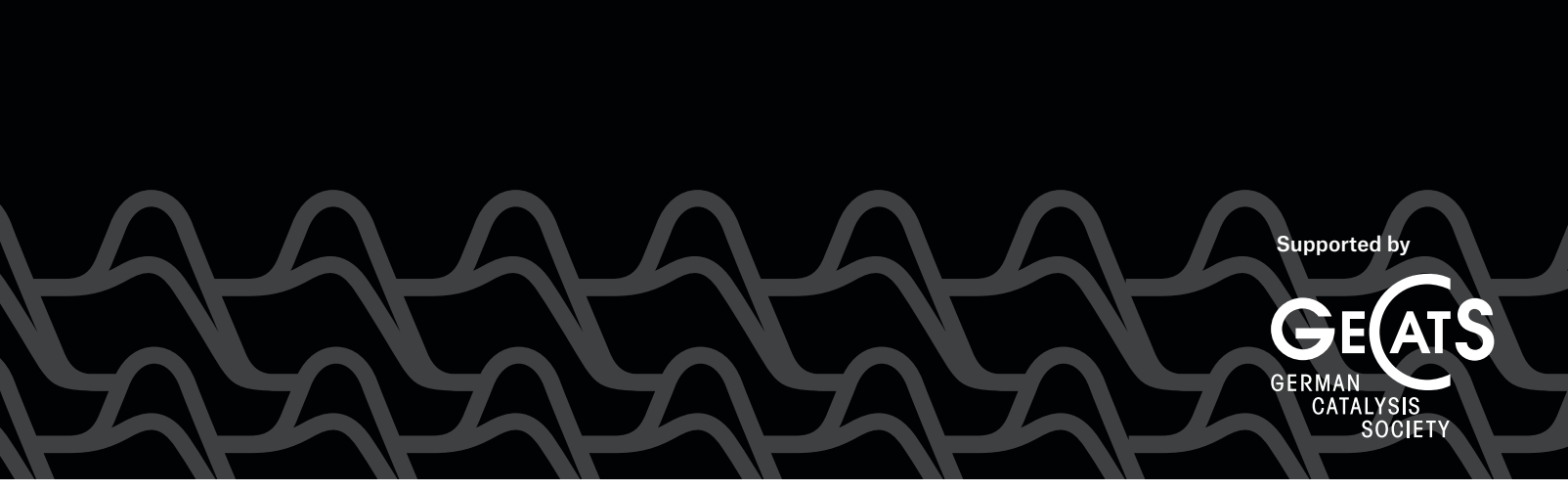

\section{Accepted Article}

Title: Heterogeneous formic acid production by hydrogenation of $\mathrm{CO} 2$ catalyzed by Ir-bpy embedded in polyphenylene porous organic polymers

Authors: Niklas R. Bennedsen, David B. Christensen, Rasmus L. Mortensen, Bolun Wang, Ryan Wang, Søren Kramer, and Søren Kegnæs

This manuscript has been accepted after peer review and appears as an Accepted Article online prior to editing, proofing, and formal publication of the final Version of Record (VoR). This work is currently citable by using the Digital Object Identifier (DOI) given below. The VoR will be published online in Early View as soon as possible and may be different to this Accepted Article as a result of editing. Readers should obtain the VoR from the journal website shown below when it is published to ensure accuracy of information. The authors are responsible for the content of this Accepted Article.

To be cited as: ChemCatChem 10.1002/cctc.202100002

Link to VoR: https://doi.org/10.1002/cctc.202100002 


\title{
Heterogeneous formic acid production by hydrogenation of $\mathrm{CO}_{2}$ catalyzed by Ir-bpy embedded in polyphenylene porous organic polymers
}

\author{
Niklas R. Bennedsen ${ }^{a}$, David B. Christensen ${ }^{a}$, Rasmus L. Mortensen ${ }^{a}$, Bolun Wang ${ }^{\mathrm{b}}$, Ryan Wang ${ }^{\mathrm{b}}$, \\ Søren Kramer*a, and Søren Kegnæs*a
}

[a] N. R. Bennedsen, Dr. D. B. Christensen, R. L. Mortensen, Asst. Prof. S. Kramer, Prof. S. Kegnæs Department of Chemistry

Technical University of Denmark

2800 Kgs. Lyngby, Denmark

E-mail: sokr@kemi.dtu.dk (S. Kramer), skk@kemi.dtu.dk (S. Kegnæs).

[b] Dr. Bolun Wang, Dr. R. Wang

Department of Chemical Engineering

University College London

Torrington Place, WC1E London, United Kingdom

Supporting information for this article is given via a link at the end of the document.((Please delete this text if not appropriate))

\begin{abstract}
Heterogeneous immobilized molecular catalysis has gained significant attention as a platform for creating more efficient and selective catalysts. A promising type of immobilized molecular catalysts are made from porous organic polymers (POPs) due to their high stability, porosity, and ability to mimic the catalytic activity and selectivity of homogeneous organometallic catalysts. These properties of the POP-based systems make them very attractive as heterogeneous catalysts for hydrogenation of $\mathrm{CO}_{2}$ to formate, where predominately homogeneous systems have been applied. In this study, five POPs were synthesized and assessed in the hydrogenation of $\mathrm{CO}_{2}$ where the active catalysts were made in-situ by mixing $\mathrm{IrCl}_{3}$ and the POPs. One of the Ir/POP catalysts provided a turn-over number (TON) $>20,000$, which is among the highest for POP-based systems. Thorough characterization $\left(\mathrm{CO}_{2^{-}}\right.$and $\mathrm{N}_{2^{-}}$ physisorption, TGA, CHN-analysis, XRD, XPS, SEM, STEM and TEM) was performed. Notably, the developed Ir/POP system also showed catalytic activity for the decomposition of formic acid into $\mathrm{H}_{2}$ enabling the use of formic acid as a renewable energy carrier.
\end{abstract}

\section{Introduction}

Designing novel porous materials with immobilized active molecular sites have been of high interest for the past decades in the field of heterogeneous catalysis to access more efficient and selective catalysts. ${ }^{[1]}$ Porous organic polymers (POPs) have received significant attention as molecular catalysts for their high stability, porous nature, and high functional freedom. ${ }^{[2]}$ POPs can easily be synthetically modified with many different functionalities, in contrast to other materials such as metal- or covalent organic frameworks, aluminosilicates, and metaloxides where compositional restraints and/or required crystallinity can hinder the incorporation of different functionalities. ${ }^{[3]}$ These functionalities can be organometallic ligands with the ability to immobilize metals and thereby form active molecular heterogeneous catalysts. ${ }^{[4]}$ Furthermore, the coordination of metals to POP-based ligand sites can also prevent classical deactivation mechanism thereby providing unique catalytic activities. ${ }^{[5]}$ Alongside these properties, POPs have shown superior gas adsorption properties making them ideal candidates for catalysis involving gases. ${ }^{[6]}$ Finally, the heterogeneous skeleton of POPs facilitates its easy recovery and reuse for future and sustainable applications.

Utilization of carbon dioxide $\left(\mathrm{CO}_{2}\right)$ have been targeted as an attractive strategy to diminish its emission to the atmosphere and contribution to the climate change as a greenhouse gas. ${ }^{[7]} \mathrm{A}$ promising application is the transformation of $\mathrm{CO}_{2}$ into more valuable chemicals with examples such as formic acid (FA), methanol, and methane. ${ }^{[8]}$ The interest for renewable formation of FA has increased tremendously over the past decades due to its high volumetric capacity of hydrogen $\left(\mathrm{H}_{2}\right)$ that can be released through selective decomposition. ${ }^{[9]}$ This makes FA an attractive organic liquid hydrogen carrier (LOHC), which can remove the otherwise need for high pressure containers in storage and transportation of $\mathrm{H}_{2} \cdot{ }^{[10]}$ The released $\mathrm{H}_{2}$ can be used as an excellent green, renewable, and sustainable source of energy with its a high gravimetric energy density, which can replace the need for fossil fuels and thereby diminish the environmental impact currently seen throughout the world. ${ }^{[11]}$ The formation of FA by hydrogenation of $\mathrm{CO}_{2}$ provides a neutral carbon balance and helps in the utilization of $\mathrm{CO}_{2}$ as a valuable resource. ${ }^{[8 c, 12]}$ Although the hydrogenation transformation is not thermodynamically favourable, the reaction can be driven by trapping the generated FA as formate. ${ }^{[13]}$ Currently, state-of-theart homogeneous catalysts for hydrogenation of $\mathrm{CO}_{2}$ to formate use precious metal-based catalyst, such as $\mathrm{Ir}, \mathrm{Rh}, \mathrm{Ru}$, and $\mathrm{Pd}$ in alkaline aqueous media. ${ }^{[14]}$ Although these homogeneous precious metal catalysts provide high turnover numbers (TON) and turnover frequencies (TOF), they do not have the same green and sustainable properties as heterogeneous catalysts. Thus, novel and active heterogeneous catalysts are very attractive for accommodating the demands for FA as a green and sustainable hydrogen carrier, which helps the utilization of $\mathrm{CO}_{2}$.

The most frequently used industrial catalysts are metal nanoparticles on porous supports, but these catalysts lack activity and selectivity in the formation of formate. ${ }^{[8]}$ Given the unique properties of POPs containing organometallic molecular catalysts, 
these new materials hold promise for addressing the issues with activity and selectivity for heterogeneous catalysis. So far, there are only sparse reports on the use of POPs for formic acid production from $\mathrm{CO}_{2}$; however, these reports already display very promising results. ${ }^{[15,16,17,18]}$ For example, in the state-of-the-art, Yoon et al. have demonstrated that an iridium containing phenanthroline-based POP catalyst can afford a TON of 14,400 for the hydrogenation of $\mathrm{CO}_{2}$ to formate. ${ }^{[15 e]}$ The same group have also published a covalent triazine POP capable of forming a $\operatorname{Ir}(\mathrm{III})-$ $\mathrm{N}$-heterocyclic carbene complex achieving a TON of $24,300 . .^{15 c]}$ We have previously developed a polyphenylene (PP) POP which did not contain organometallic ligand sites. ${ }^{[19]}$ Instead of creating a molecular catalyst the PP was used as a support material for Pd nanoparticles. Recently, Wang et al. have shown that a sulfonated PP can hydrate alkyne bonds showing the versatility of such a material. ${ }^{[20]}$ Yet, as the PP POP is made up exclusively of aromatic $\mathrm{sp}^{2}$-carbons in a ordered structure, it is very robust with inherent high porosity, and these features could make it ideal for applications in high-pressure reactions like the hydrogenation of $\mathrm{CO}_{2}$ to formate.

Here, we report the synthesis of novel PP-based POPs with organometallic ligands, bipyridine or phenanthroline, incorporated into the polymer skeleton. Upon in-situ ligation to iridium, the best Ir-POP can catalyze hydrogenation of $\mathrm{CO}_{2}$ to formate with a TON $>20,000$ under reaction conditions comparable to previous literature reports $\left(140{ }^{\circ} \mathrm{C}, 56\right.$ bar $\left.1: 1 \mathrm{H}_{2}: \mathrm{CO}_{2}\right)$. The influence on the TON by varying the ligand and ligand density is examined. The synthesized materials are characterized by $\mathrm{TGA}, \mathrm{CO}_{2}$ - and $\mathrm{N}_{2}$-physisorpion, SEM, STEM, TEM, XPS, and CHN-analysis. In addition, post-reaction characterization is conducted to assess material changes during the catalytic reaction. Interestingly, the corresponding homogeneous catalysts led to much lower TONs, thus highlighting the essential role of the POP in the catalytic performance. Finally, we demonstrate that the same catalyst is active in the selective dehydrogenation of FA. This is the first reported POP catalyst system capable of both forming and decomposing FA selectively, accordingly it can help advancing $\mathrm{H}_{2}$ as a renewable and sustainable energy source.

\section{Results and Discussion}

\section{Synthesis and characterization}

One of the characteristics of the synthesized POPs is that the polymerization technique only forms aromatic $\mathrm{sp}^{2}$-carbons resulting in polymers which are more chemically and physically stable than many other polymers. ${ }^{[2 \mathrm{~d}]}$ The expected high thermal stability was also observed by thermogravimetric analysis (Figure 1a). The POPs are seemingly stable in air up to at least $300^{\circ} \mathrm{C}$ and a significant mass loss is only observed above $500^{\circ} \mathrm{C}$. An amorphous structure is seen in XRD (Figure S2), but the polymer appears homogeneous in structure with similar morphology throughout the whole sample in SEM (Figure 1b). The nitrogen content of the synthesized POPs was assessed by $\mathrm{CHN}$-analysis and XPS (Figure 1c). Both analyses reveal an increase in nitrogen content in our series of bpy-based POPs with bpy-PP-POP having the lowest nitrogen content and 4xbpy-PP-POP the highest; however, the increase does not match the expected $1: 2: 4$ ratio but rather a $1: 1.5: 2.5$ ratio based on the $\mathrm{CHN}$ values. The adsorption properties were examined by $\mathrm{N}_{2}$-physisorption initially where none of the POPs containing ligands showed any porosity (Figure S3). Notably, the change of adsorbate to $\mathrm{CO}_{2}$ instead of $\mathrm{N}_{2}$ showed that all the POPs are porous and capable of adsorbing $\mathrm{CO}_{2}$ (Figure 1d). ${ }^{[21]}$ Furthermore, a clear trend was observed as increasing the bpy density in the POP decreases the porosity. The change in porosity is probably due to changes in the POP structure when introducing the more of the linear bpy (see Table S2 for measured BET surface areas). XPS analysis of the carbon in the polymer confirms that only one signal is present corresponding to $\mathrm{C}-\mathrm{C}$ bonds with no indication of oxidation from the $\mathrm{H}_{2} \mathrm{O}_{2}$ treatment (Figure S5). The nitrogen in the bpy-PP-POP is present as only one specie that has a binding energy corresponding to pyridinic nitrogen (Figure 1e). ${ }^{[22]}$ The introduction of more bipyridine sites or replacing bpy with Phen into the skeleton (2xbpy-PP-POP, 4xbpy-PP-POP, or Phen-PP$\mathrm{POP})$ did not show any significant difference from the bpy-PP. POP material (see Figure S6). Unfortunately, supplementary FTIR spectroscopy did not provide any useful data. Nevertheless, these results are in agreement with the synthesized material being a polyphenylene POP with either bpy or Phen functionality


in the skeleton (see Table S3 for additional values from $\mathrm{CHN}$ analysis and Figure S7 for a TEM image).

Scheme 1. Illustration of the synthesis and catalytic reaction of the PP-POPs. 
Figure 1. Characterization of synthesized POP. a) The thermal stability

a

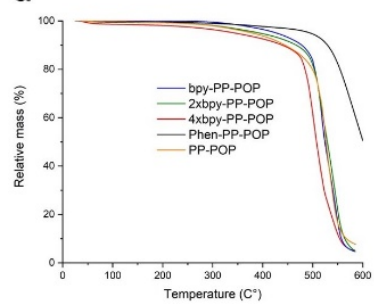

\begin{tabular}{llll}
\hline POP & $\begin{array}{l}\mathrm{CHN} \text {-analysis } \\
\mathrm{N} \text { (mass \%) }\end{array}$ & $\begin{array}{l}\text { XPS } \\
\mathrm{N} \text { (mass \%) }\end{array}$ & $\begin{array}{l}\text { Nitrogen content relative } \\
\text { to bpy-PP-POP }\end{array}$ \\
\hline bpy-PP-POP & $3.28 \%$ & $4.91 \%$ & 1.0 \\
2xbpy-PP-POP & $4.90 \%$ & $6.30 \%$ & 1.5 \\
4xbpy-PP-POP & $8.22 \%$ & $9.62 \%$ & 2.5 \\
Phen-PP-POP & $3.81 \%$ & $2.12 \%$ & 1.2 \\
PP-POP & $0.46 \%$ & $0.00 \%$ & 0.1 \\
\hline
\end{tabular}

d
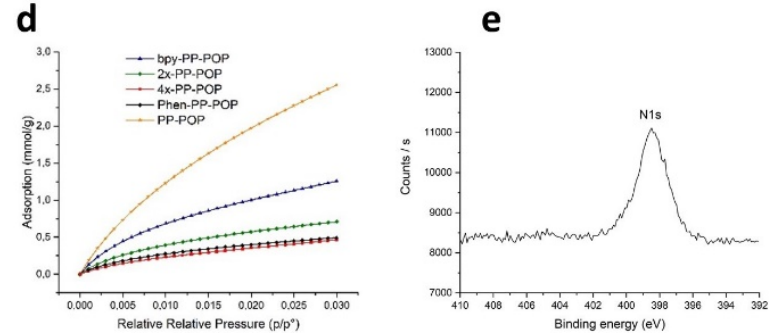

evaluated from TGA. b) SEM image of the bpy-PP-POP. c) Compositional analysis of the nitrogen content of the POPs. d) $\mathrm{CO}_{2}$-adsorption isotherms of the POPs conducted at $0{ }^{\circ} \mathrm{C}$. e) XPS signal from the N1s scan shown for the bpy-PP-POP.

\section{Hydrogenation of $\mathrm{CO}_{2}$}

With four different POPs containing organometallic ligand sites in hand, we tested the POPs in the catalytic hydrogenation of $\mathrm{CO}_{2}$ to formate. In our test setup, the POP and an iridium precursor were mixed in a $1 \mathrm{M}$ aqueous solution of $\mathrm{Et}_{3} \mathrm{~N}$ inside a steel reactor. The total pressure inside the reactor was regulated to 56 bar of $\mathrm{CO}_{2}$ and $\mathrm{H}_{2}$ in a 1:1 ratio before being heated to the specified temperature (an example of the pressure profile during an experiment is shown in Figure S9). The POPs with either phenanthroline or bipyridine in the skeleton both showed activity in the formation of FA, but the POP based on bipyridine displayed superior activity (Table 1 , entry 1 and 2 ). Lowering the iridium concentration to $10 \mu \mathrm{M}$ for the bpy-PP-POP provided an impressive TON of 20,041 (entry 3 ). The addition of more POP did not improve the catalytic performance (entry 4). Replacing the original POP with derivatives that have a higher concentration of bipyridine in the skeleton (2xbpy-PP-POP and 4xbpy-PP-POP) led to significantly lower TONs (entry 5 and 6 ). This may be correlated to their inferior porosity seen from the $\mathrm{CO}_{2}$-adsorption experiment. Increasing the reaction time to 48 hours did not improve the yield (entry 7 ). Switching the iridium precursor from $\mathrm{IrCl}_{3}$ to $\left[\mathrm{IrCp}{ }^{*} \mathrm{Cl}\right]_{2}$ or $[\mathrm{Ir}(\mathrm{cod}) \mathrm{MeO}]_{2}$ did not provide higher activity (entry 8 and 9). Lowering the reaction temperature to $120{ }^{\circ} \mathrm{C}$ decreased the activity significantly (entry 10 ). A test reaction with commercially available material of iridium nanoparticles on carbon (Ir/C) showed no significant catalytic activity (entry 11).
Table 1. The catalytic performance of the synthesized POPs in the presence of

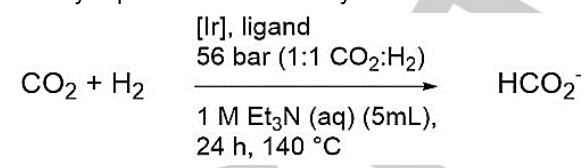

\begin{tabular}{|c|c|c|c|c|c|}
\hline Entry & POP & {$[\mathrm{Ir}]$ (conc.) } & Yield $^{[a]}$ & $\mathrm{TON}^{[\mathrm{b}]}$ & \\
\hline 1 & Phen-PP-POP & $\mathrm{IrCl}_{3} \cdot \mathrm{xH}_{2} \mathrm{O}(100 \mu \mathrm{M})$ & $12 \%$ & 1336 & \\
\hline 2 & bp) & $\mathrm{IrCl}_{3} \cdot x \mathrm{H}_{2} \mathrm{O}(100 \mu \mathrm{M})$ & $42 \%$ & 4676 & \\
\hline $3^{[c]}$ & POP & $\mathrm{IrCl}_{3} \cdot x \mathrm{H}_{2} \mathrm{O}(10 \mu \mathrm{M})$ & $18 \%$ & 20041 & ㅁ \\
\hline $4^{[\mathrm{d}]}$ & $\mathrm{bp}$ & $\mathrm{IrCl}_{3} \cdot \mathrm{xH}_{2} \mathrm{O}(10 \mu \mathrm{M})$ & $16 \%$ & 17814 & 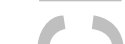 \\
\hline $5^{[e]}$ & 2xbpy-PP-POP & $\mathrm{IrCl}_{3} \cdot \mathrm{xH}_{2} \mathrm{O}(10 \mu \mathrm{M})$ & $5 \%$ & 5567 & \\
\hline $6^{[\mathrm{e}]}$ & 4xbpy-PP-POP & $\mathrm{IrCl}_{3} \cdot \mathrm{xH}_{2} \mathrm{O}(10 \mu \mathrm{M})$ & $5 \%$ & 5567 & \\
\hline $7^{[f]}$ & bpy-PP-POP & $\mathrm{IrCl}_{3} \cdot \times \mathrm{H}_{2} \mathrm{O}(10 \mu \mathrm{M})$ & $15 \%$ & 16701 & \\
\hline 8 & bpy-PP-POP & {$\left[\mathrm{IrCp}{ }^{*} \mathrm{Cl}\right]_{2}(10 \mu \mathrm{M})$} & $12 \%$ & 13360 & \\
\hline 9 & bpy-PP-POP & {$[\operatorname{lr}(\operatorname{cod}) \mathrm{MeO}]_{2}(10 \mu \mathrm{M})$} & $10 \%$ & 11134 & \\
\hline $10^{[g]}$ & bpy-PP-POP & $\mathrm{IrCl}_{3} \cdot \mathrm{xH}_{2} \mathrm{O}(10 \mu \mathrm{M})$ & $2 \%$ & 2227 & \\
\hline $11^{[\mathrm{h}]}$ & & $\mathrm{Ir} / \mathrm{C}(100 \mu \mathrm{M})$ & $3 \%$ & 3340 & \\
\hline $12^{[\mathrm{e}]}$ & 2,2'-bipyridine & $\mathrm{IrCl}_{3} \cdot \mathrm{xH}_{2} \mathrm{O}(10 \mu \mathrm{M})$ & $<1 \%$ & - & \\
\hline $13^{[i]}$ & - & $\mathrm{K}\left[\mathrm{IrbpyCl}_{4}\right]$ & $2 \%$ & 2227 & \\
\hline $14^{[i]}$ & $\begin{array}{l}\text { bpy-PP-POP + 2,2'- } \\
\text { bipyridine }\end{array}$ & $\mathrm{IrCl}_{3} \cdot \mathrm{xH}_{2} \mathrm{O}(10 \mu \mathrm{M})$ & $6 \%$ & 6080 & \\
\hline 15 & bpy-PP-POP (used) & - & $12 \%$ & 13361 & \\
\hline 16 & bpy-PP-POP (used) & $\mathrm{IrCl}_{3} \cdot \mathrm{xH}_{2} \mathrm{O}(10 \mu \mathrm{M})$ & $17 \%$ & 18928 & \\
\hline 17 & - & - & $<1 \%$ & - & \\
\hline 18 & - & $\mathrm{IrCl}_{3} \cdot \mathrm{xH}_{2} \mathrm{O}(10 \mu \mathrm{M})$ & $<1 \%$ & - & \\
\hline 19 & bpy-PP-POP & - & $6 \%$ & 6680 & \\
\hline
\end{tabular}

an iridium precursor for the hydrogenation of $\mathrm{CO}_{2}$ to formate.

[a] Yield quantified by ${ }^{1} \mathrm{H}-\mathrm{NMR}$ using $\mathrm{D}_{2} \mathrm{O}$ as solvent and $\mathrm{Et}_{3} \mathrm{~N}$ as a standard. [b] TON calculated by the following equation: the $n($ formate $) / n(I r)$ where $n$ (formate) is given by yield ${ }^{*}\left(E_{3} N\right)$ and the total amount of iridium is estimated based on a iridium content of $52 \%$ for the $\mathrm{IrCl}_{3} \cdot \mathrm{xH}_{2} \mathrm{O}$ salt. [c] This TON value corresponds to a TOF of $835 \mathrm{~h}^{-1}$. [d] Twice the normal amount of POP. [e] The overall amount of bipyridine was kept constant. [f] Reaction time was 48 hours [g] The reaction temperature was decreased to $120^{\circ} \mathrm{C}$. [h] Commercially available $\mathrm{Ir} / \mathrm{C}$. [i] The $\mathrm{K}\left[\mathrm{IrbpyCl}_{4}\right]$ complex was synthesized according to reported literature. ${ }^{[24]}[j]$ The amount of added 2,2'-bipyridine is 1 equivalent of the added iridium.

To compare our heterogeneous catalyst system with the corresponding homogeneous catalyst system, we performed the $\mathrm{CO}_{2}$ hydrogenation with $\mathrm{IrCl}_{3} \cdot \mathrm{xH}_{2} \mathrm{O} / 2,2$ '-bipyridine (entry 12). Surprisingly, this homogeneous catalyst system did not display any significant activity indicating that the incorporation of the ligand into the POP skeleton is crucial for achieving high TONs for this transformation. Also, the use of a homogeneous 
monobipyridine iridium complex as catalyst was unsuccessful (entry 13). To gain further insight into the potential reason for the beneficial effect of the POP, we added 2,2'-bipyridine to a reaction with bpy-PP-POP (entry 14). Notably, the reaction was significantly inhibited by the presence of the homogeneous ligand. Previous reports have indicated that common deactivation mechanisms e.g. formation of inactive dimers and saturated complexes can be avoided with the incorporation of the ligand into a rigid $\mathrm{POP}$ backbone, and also that active complexes can only be formed with POP-based ligands providing unique properties for catalysis. ${ }^{[5,23]}$ Accordingly, we hypothesize that the rigid bpyPP-POP stabilizes a catalytically active Ir/mono-bpy species and prevents the formation of more stable yet inactive bis- or trischelated Ir/bpy species and dimers, which can be accessed readily under homogeneous conditions (Scheme 2 ).

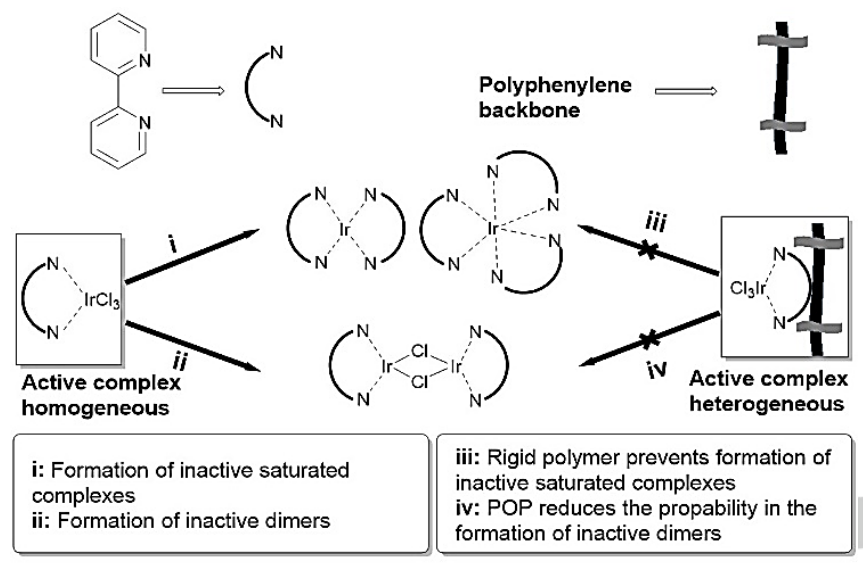

Scheme 2. Potential deactivation pathways for homogeneous systems which are made inaccessible by the rigid structure of the POP.

To investigate the recyclability of the bpy-PP-POP catalyst material, without addition of new $\mathrm{Ir}$, the material was recovered by centrifugation and rinsed with water. Subsequently, the recovered catalyst material was subjected to a fresh solution of $\mathrm{Et}_{3} \mathrm{~N}$ under $\mathrm{CO}_{2}$ and $\mathrm{H}_{2}$ pressure. The POP-based catalyst material is still active, but a loss of yield is observed (Table 1, entry 15). However the original activity can be recovered by the addition of fresh $\mathrm{IrCl}_{3} \cdot \mathrm{xH}_{2} \mathrm{O}$ (entry 16). Control experiments showed that the reactor and $\mathrm{IrCl}_{3} \cdot \mathrm{xH}_{2} \mathrm{O}$ are not active by itself (entries 17-18). The bpy-PP-POP alone does show some activity, but it is less active than in the presence of iridium (entry 19). Potential Pd residues may still be present in the POP despite the post polymerization treatments. The PP-POP can be synthesized Pd free ${ }^{[19]}$, however a small signal can be seen from Pd in a survey XPS scan (Figure S4). Despite the background reaction, the TON value is dramatically increased with the addition of iridium, thus, the majority of the observed activity is asummed to arise from the iridium-catalyzed reaction.

The used bpy-PP-POP catalyst was characterized by STEM to identify potential changes in the material and help clarifying possible deactivation mechanisms (Figure 2). The STEM images of the used catalyst reveal the presence of iridium nanoparticles that are distributed throughout the whole sample and have a very narrow size distribution (2-4 nm). Albeit, iridium nanoparticles on carbon have previously shown to be inactive for the hydrogenation of $\mathrm{CO}_{2}$ under our conditions (Table 1, entry 11). $\mathrm{XRF}$ analysis reveals the presence of approximately $1 \mu \mathrm{M}$ iridium in a filtrated reaction mixture (see Table S4). These two observations suggest that the observed catalytic deactivation observed upon recycling can arise from either/both decomposition of $\operatorname{Ir}(\mathrm{III})$ into nanoparticles or Ir not being strongly coordinated to the POP. Yet, the addition of fresh $\mathrm{IrCl}_{3} \cdot \mathrm{xH}_{2} \mathrm{O}$ can re-establish the activity showcasing the robustness of the POP itself.

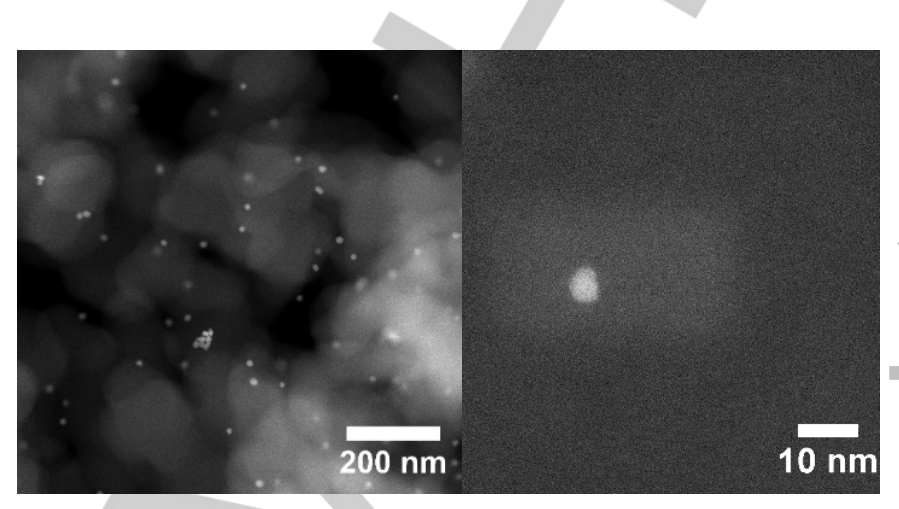

Figure 2. STEM images of the used Ir-bpy-PP-POP showing the presence of small iridium nanoparticles.

The observed inability of the corresponding homogeneous catalyst systems to replicate the high TON obtained with the POP supports the intended heterogeneous nature of the catalyst. Nonetheless, homogeneous species which can only be formed in the presence of the POP could potentially be catalytically active in the hydrogenation. To investigate this possibility, a filtration experiment was carried out (Scheme 3). The reaction was stopped after 2 hours, filtered to remove the POP from the reaction mixture, and started again by refilling with $\mathrm{CO}_{2}$ and $\mathrm{H}_{2}$. The very limited activity in the liquid phase shows that the origin of the catalytic activity is heterogeneous in nature.

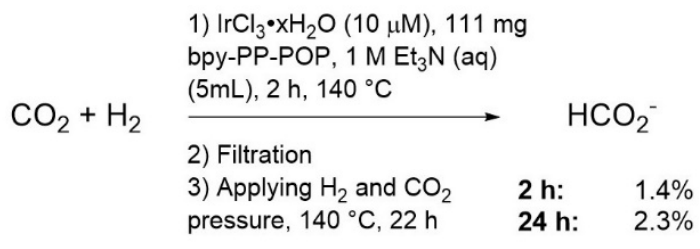

Scheme 3. Filtration experiment with the obtained yield after either 2 or $24 \mathrm{~h}$ at $140{ }^{\circ} \mathrm{C}$.

\section{Selective dehydrogenation of formic acid}

The path towards a sustainable and renewable future utilization of $F A$ as hydrogen energy carrier requires both the formation and selective dehydrogenation of FA. Reports of systems that can catalyze both directions are rare and highly attractive. ${ }^{[25]}$ In that perspective, we tested if our $\mathrm{IrCl}_{3} /$ bpy-PP-POP-system was active in the dehydrogenation of FA. In our setup, the dehydrogenation of FA is conducted in a continuous vapour phase setup by bubbling FA with a stream of nitrogen and passing the saturated gas stream over a fixed reactor bed. The yield of $\mathrm{H}_{2}$ is then measured while the temperature of the reactor bed is increased. Notably, activity was observed at temperatures from $160{ }^{\circ} \mathrm{C}$ illustrating the potential of our POP as a multifunctional catalyst capable of both forming and decomposing FA (Figure 3). 
Performing the decomposition of FA with minimal formation of $\mathrm{CO}$ is crucial to avoid poisoning of the state-of-the-art platinum catalysts used in the fuel cells, and therefore this reaction is typically carried out at low temperatures to get very high selectivity. ${ }^{[26]}$ Remarkably, our POP-based system is very selective up to $190^{\circ} \mathrm{C}(\mathrm{CO}<0.01 \%$; Figure $\mathrm{S} 11)$.

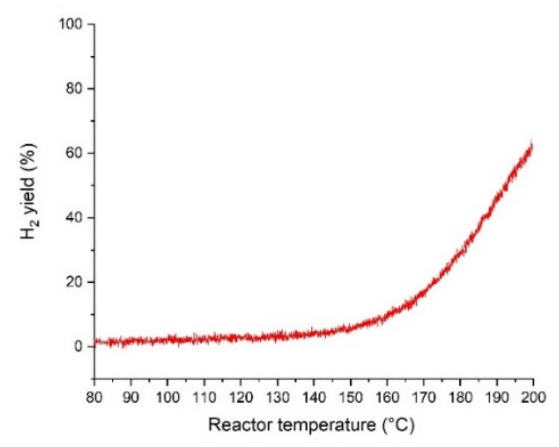

Figure 3. Activity plot with the yield of $\mathrm{H}_{2}$ as a function of temperature in the decomposition of FA.

\section{Conclusion}

In summary, we have made a series of polyphenylene-based POPs with different ligand types and concentration of the ligand in the skeleton of the POP. The POPs are amorphous with excellent thermal stability up to at least $400{ }^{\circ} \mathrm{C}$ in air. The synthesized POPs were assessed in the hydrogenation of $\mathrm{CO}_{2}$ to form $F A$ as a renewable hydrogen energy carrier creating a neutral carbon balance and utilization the abundant $\mathrm{CO}_{2}$. The results show that both ligand type and concentration of the ligand affects the catalytic performance. The best catalytic performance was observed with bpy-PP-POP which led to a TON $>20,000$. The beneficial effect of incorporating the bipyridine ligand into a POP structure was clearly demonstrated with the much lower activity achieved for the corresponding homogeneous iridium-bipyridine systems. A decrease in activity was observed when recycling the catalyst material, however, the activity can be recovered by introducing fresh iridium to the reaction mixture, thus demonstrating the robustness of the POP. Electron microscopy revealed that the most likely deactivation mechanism is formation of inactive iridium nanoparticles. Finally, we demonstrated that our catalytic system can also selectively decompose FA into $\mathrm{H}_{2}$ thereby highlighting the potential of POP catalysts in the implementation of FA as a renewable energy source.

\section{Experimental Section}

See supporting information for analytical and synthetic procedures.

\section{Acknowledgements}

The authors are grateful for funding from the Independent Research Fund Denmark (grant no. 6111-00237), from Villum fonden (Grant No. 13158), and from Haldor Topsøe A/S. S. Kramer is deeply appreciative of generous financial support from the Lundbeck Foundation (Grant No. R250-2017-1292) and the Technical University of Denmark.

Keywords: $\mathrm{CO}_{2}$ utilization $\cdot$ heterogeneous catalyst $\cdot$ porous organic polymers $\cdot$ hydrogenation of $\mathrm{CO}_{2} \cdot$ hydrogen capture and release.

[1] a) J. Thomas, R. Raja, D. Lewis, Angew. Int. Ed. 2005, 44, 6456-6482 b) C. Copéret, M. Chabanas, R. Saint-Arroman, J.-M. Basset, J.-M., Angew. Chem. Int. Ed. 2008, 42, 156-181, c) J. Pelletier, J.-M. Basset, Acc. Chem. Res., 2016, 49, 664-677, d) X. Cui, W. Li, P. Ryabchuk, K. Junge, M. Beller, Nat. Chemistry, 2018, 1, 385-397, e) M. Wasson, C Buru, Z. Chen, T. Islamoglu, O. Farha, Appl. Catal. A Gen., 2019, 586, 117214

[2] a) P. Kaur, J. Hupp, S. Nguyen, ACS Catal., 2011, 1, 819-835, b) Y. Zhang, N. Riduan, Chem. Soc. Rev., 2012, 41, 2083-2094, c) Q. Sun, Z Dai, X. Meng, F.-S. Xiao, Chem. Soc. Rev., 2015, 44, 6018-6034, d) S. Kramer, N. Bennedsen, S. Kegnæs, ACS Catal., 2018, 8, 6961-6982.

[3] a) Y. Ma, W. Tong, H. Zhou, S. Suib, Micropor. Mesopor. Mat., 2000, 37, 243-252, b) Y. Wang, H. Arandiyan, J. Scott, A. Bagheri, H. Dai, R. Amal, J. Mater. Chem. A., 2017, 5, 8825-8864, c) A. Dhakshinamoorthy, A. Asiri, H. Garcia, ACS Catal., 2019, 9, 1081-1102, d) L. Gonçalves, D. Christensen, M. Meledina, L. Salonen, D. Petrovykh, J. Sousa, O. Soares, M. Pereira, S. Kegnæs, Y. Kolen'ko, Catal. Sci. Technol., 2020, 10, 19911995.

[4] a) W. Wang, A. Zheng, P. Zhao, C. Xia, F. Li, ACS Catal., 2014, 4, 321 327, b) X. Wang, S. Lu, J. Li, Y. Liu, C. Li, Catal. Sci. Technol., 2015, 5 2585-2589, c) Z. Dai, Q. Sun, X. Liu, C. Bian, Q. Wu, S. Pan, L. Wang, X. Meng, F. Deng, F.-S. Xiao, J. Catal., 2016, 338, 202-209, d) Y. Xu, T. Wang, Z. He, M. Zhou, W. Yu, B. Shi, K. Huang, Appl. Catal. A Gen., 2017, 541,112-119, e) R. Cai, X. Ye, Q. Sun, Q. He, Y. He, S. Ma, X. Shi, ACS Catal., 2017, 7, 1087-1092.

[5] a) S. Kraft, R. Sánchez, A. Hock, ACS Catal., 2013, 3, 826-830, b) T. Iwai, T. Harada, H. Shimada, K. Asano, M. Sawamura, ACS Catal., 2017 7, 1681-1692.

[6] a) P. Bjanja, A. Modak, A. Bhaumik, ChemCatChem, 2019, 11, 244-257, b) E. Sanz-Pérez, L. Rodríguez-Jardon, A. Arencibia, R. Sanz, M Iglesias, E. Maya, J. CO2 Util., 2019, 30, 183-192.

[7] a) M. Aresta, A. Dibenedetto, A. Angelini, J. CO2 Util., 2013, 3-4, 65-73 b) M. Aresta, A. Dibenedetto, A. Angelini, Chem. Rev., 2014, 114, 1709 1742, c) A. Parvez, M. Afzal, T. Hebb, J. CO2 Util., 2020, 40, 101217.

[8] a) G. Gunasekar, K. Park, K.-D. Jung, S. Yoon, Inorg. Chem. Front., 2016, 3, 882-895, b) X. Su, J. Xu, B. Liang, H. Duan, B. Hou, Y. Huang J. Energy Chem., 2016, 25, 553-565, c) A. Álverez, A. Bansode, A Urakawa, A. Bavykina, T. Wezendonk, M. Makkee, J. Gascon, F. Kapteijn, Chem. Rev., 2017, 117, 9804-9838, d) D. Bulushev, J. Ross Catal. Rev. Sci. Eng., 2018, 60, 566-593, e) S. Dang, H. Yang, P. Gao, H. Wang, X. Li, W. Wei, Y. Sun, Catal. Today, 2019, 330, 61-75, f) X. Chen, Y. Liu, J. Wu, Mol. Catal., 2020, 483, 110716.

[9] a) A. Klerke, S. Klitgaard, R. Fehrmann, Catal. Lett., 2009, 130, 541-546 b) A. Züttel, P. Mauron, S. Kato, E. Callini, M. Holzer, J. Huang, Chimia 2015, 69, 264-268, c) A. Singh, S. Singh, A. Kumar, Catal. Sci. Technol., 2016, 6, 12-40, d) A. Gallas-Hulin, J. Mielby, S. Kegnæs, ChemistrySelect, 2016, 1, 3941-3945, e) H. Kawanami, Y. Himeda, G. Laurenczy, Adv. Inorg. Chem., 2017, 70, 395-427, f) J. Eppinger, K.-W. Huang, ACS Energy Lett., 2017, 2, 188-195, g) K. Müller, K. Brooks, T. Autrey, Energy Fuels, 2017, 31, 12603-12611, h) J. Mielby, A. KunovKruse, S. Kegnæs, J. Catal., 2017, 345, 149-156, i) S. Zacho, J. Mielby, S. Kegnæs, Catal. Sci. Technol., 2018, 8, 4741-4746, j) H. Zhong, M. Iguchi, M. Chatterjee, Y. Himeda, Q. Xu, H. Kawanami, Adv. Sustain. Syst., 2018, 2, 1700161.

[10] a) P. Preuster, C. Papp, P. Wasserscheid, Acc. Chem. Res., 2017, 50 74-85, b) P. Aakko-Saksa, C. Cook, J. Kiviaho, T. Repo, J. Power Sources, 2018, 396, 803-823, c) M. Niermann, S. Drünert, M. Kaltschmitt, K. Bonhoff, Energy Environ. Sci., 2019, 12, 290-307, d) M. Niermann, A. Beckendorff, M. Kaltschmitt, K. Bonhoff, Int. J. Hydrog. Energy, 2019, 44 6631-6654, e) P. Modisha, C. Ouma, R. Garidzirai, P. Wasserscheid, D. Bessarabov, Energy Fuels, 2019, 33, 2778-2796. 
[11] J. Abe, A. Popoola, E. Ajenifuja, O. Popoola, Int. J. Hydro. Energy, 2019, 44, 15072-15086.

[12] W.-H. Wang, Y. Himeda, J. Muckerman, E. Fujita, Adv. Inorg. Chem., 2014, 66, 189-222.

[13] C. Jia, J. Gao, Y. Dai, J. Zhang, Y. Yang, J. Energy. Chem., 2016, 25, 1027-1037.

[14] Y. Himeda, Eur. J. Inorg. Chem., 2007, 3927-3941, b) R. Tanaka, M. Yamashita, K. Nozaki, J. Am. Chem. Soc., 2009, 131, 14168-14169, c) S. Sanz, A. Azua, E. Peris, Dalton Trans., 2010, 39, 6339-6343, d) W. Wang, S. Wang, X. Ma, J. Gong, Chem. Soc. Rev., 2011, 40, 3703-3727.

[15] For examples with POPs see: a) N. McNamara, J. Hicks, ChemSusChem, 2014, 7, 1114-1124, b) Z.-Z. Yang, H. Zhang, B. Yu, Y. Zhao, G. Ji, Z. Liu, Chem. Commun., 2015, 51, 1271-1274, c) G. Gunasekar, K. Park, V. Kim, K.-D. Jung, S. Yoon, Chem. Mater., 2017, 29, 6740-6748, d) X. Shao, X. Yang, J. Xu, S. Liu, S. Miao, X. Liu, X. Su, H. Duan, Y. Huang, T. Zhang, Chem., 2019, 5, 693-705, e) G. Gunasekar, S. Yoon, J. Mater. Chem. A., 2019, 7, 14019-14026.

[16] For examples with COFs see: a) K. Park, G. Hariyanandam, N. Prakash, K.-D. Jung, S. Yoon, ChemSusChem, 2015, 8, 3410-3413, b) G. Hariyanandam, D. Hyun, P. Natarajan, K.-D. Jung, S. Yoon, Catal. Today, 2016, 265, 52-55, c) K. Park, G. Gunasekar, S.-H. Kim, H. Park, S. Kim, K. Park, K.-D. Jung, S. Yoon, Green Chem. 2020, 22, 1639-1649.

[17] For examples with MOFs see: a) D. Sun, Y. Fu, W. Liu, L. Ye, D. Wang, L. Yang, X. Fu, Z. Li, Chem. Eur. J., 2013, 19, 14279-14285, b) M. Chambers, X. Wang, N. Elgrishi, C. Hendon, A. Walsh, J. Bonnefoy, J. Canivet, E. Quadrelli, D. Farrusseng, C. Mellot-Draznieks, M. Fontecave, ChemSusChem, 2015, 8, 603-608, c) H. Fei, M. Sampson, Y. Lee, C. Kubiak, S. Cohen, Inorg. Chem., 2015, 54, 6821-6828, d) B. An, L. Zeng M. Jia, Z. Li, Z. Lin, Y. Song, Y. Zhou, J. Cheng, C. Wang, W. Lin, J. Am. Chem. Soc., 2017, 139, 17747-17750, e) E. Gutterød, S. Øien-Ødegaard, K. Bossers, A.-E. Nieuwelink, M. Manzoli, L. Braglia, A. Lazzarini, E. Borfecchia, S. Ahmadigoltapeh, B. Bouchevreau, B. Lønstad-Bleken, R. Henry, C. Lamberti, S. Bordiga, B. Weckhuysen, K. Lillerud, U. Olsbye, Ind. Eng. Chem. Res., 2017, 56, 13206-13218, f) P. Tshuma, B. Makhubela, L. Öhrström, S. Bourne, N. Chatterjee, I. Beas, J. Darkwa, G. Mehlana, RSC. Adv., 2020, 10, 3593-3605.

[18] Other examples of heterogeneous catalysts see: a) $Y$. Zhang, J. Fei, $Y$. Yu, X. Zheng, Catal. Commun., 2004, 5, 643-646, b) Z. Xu, N. McNamara, G. Neumann, W. Schneider, J. Hicks, ChemCatChem, 2013, 5, 17691771, c) N. McNamara, J. Hicks, ChemSusChem, 2014, 7, 1114-1124, d) Z.-Z. Yang, h. Zhang, B. Yu, Y. Zhao, G. Ji, Z. Liu, Chem. Commun., 2015, 51, 1271, e) K. Mori, T. Taga, H. Yamashita, ACS Catal., 2017, 7, 3147-3151, f) S. De, L. Gevers, A.-H. Emwas, J. Gascon, ACS Sustainable Chem. Eng., 2019, 7, 3933-3939.

[19] F. Wang, J. Mielby, F. Richter, G. Wang, G. Prieto, T. Kasama, C. Weidenthaler, H.-J. Bongard, S. Kegnæs, A. Fürstner, F. Schüth, Angew. Chem. Int. Ed., 2014, 53, 8645-8648.

[20] Y. Liu, B. Wang, L. Kang, A. Stamatopoulos, H. Gu, F. Wang, Chem. Mater., 2020, 32, 4375-4382.

[21] J. Zhang, Z. Xia, L. Dai, Sci. Adv., 2015, 1, e1500564.

[22] a) K. Cychosz, M. Thommes, Engineering, 2018, 4, 559-566, b) M. Alkordi, R. Haikal, Y. Hassan, A.-H. Emwas, Y. Belmabkhout, J. Mater. Chem. A, 2015, 3, 22584-22590.

[23] T. Iwai, T. Harada, K. Hara, M. Sawamura, Angew. Chem. Int. Ed., 2013, 52, $12322-12326$.

[24] J. Lee, Y. Liou, W. Huang, Inorg. Chim. Acta, 2001, 319, 83-89.

[25] a) J. Hull, Y. Himeda, W.-H. Wang, B. Hasiguchi, R. Periana, D. Szalda, J. Muckerman, E. Fujita, Nat. Chemistry, 2012, 4, 383-388, b) J. Lee, J. Ryu, J. Kim, S.-W. Nam, J. Han, T.-H. Lim, S. Gautam, K. Chae, C. Yoon, J. Mater. Chem. A, 2014, 2, 9490-9495.

[26] D. Mellmann, P. Sponholz, H. Junge, M. Beller, M. Chem. Soc. Rev., 2016, 45, 3954-3988. 


\section{Entry for the Table of Contents}

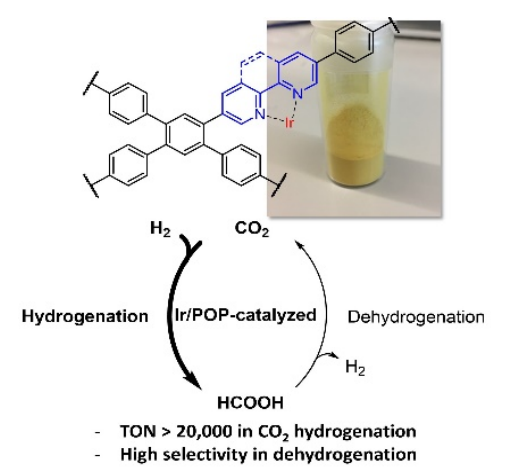

Heterogeneous molecular catalysts created from porous organic polymers (POPs) is an attractive strategy to form highly active catalysts that can easily be reused. In this article, the hydrogenation of $\mathrm{CO}_{2}$ to formic acid was catalysed by an in-situ made iridium/POP catalyst providing up to $>20,000 \mathrm{TON}$. The same system was active in the reversible dehydrogenation of formic acid enabling the use of formic acid as a liquid organic hydrogen carrier.

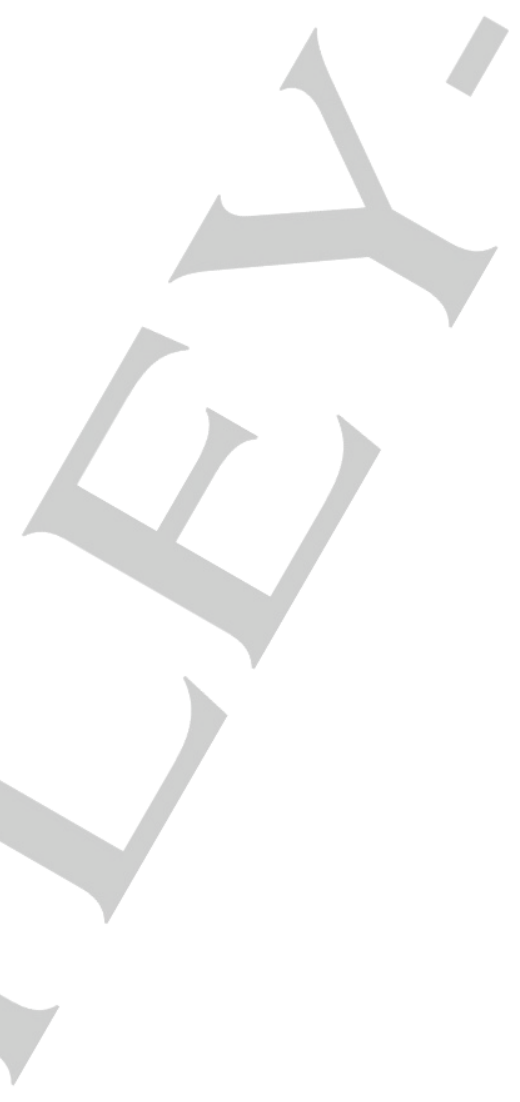




\section{WILEY-VCH}

FULL PAPER
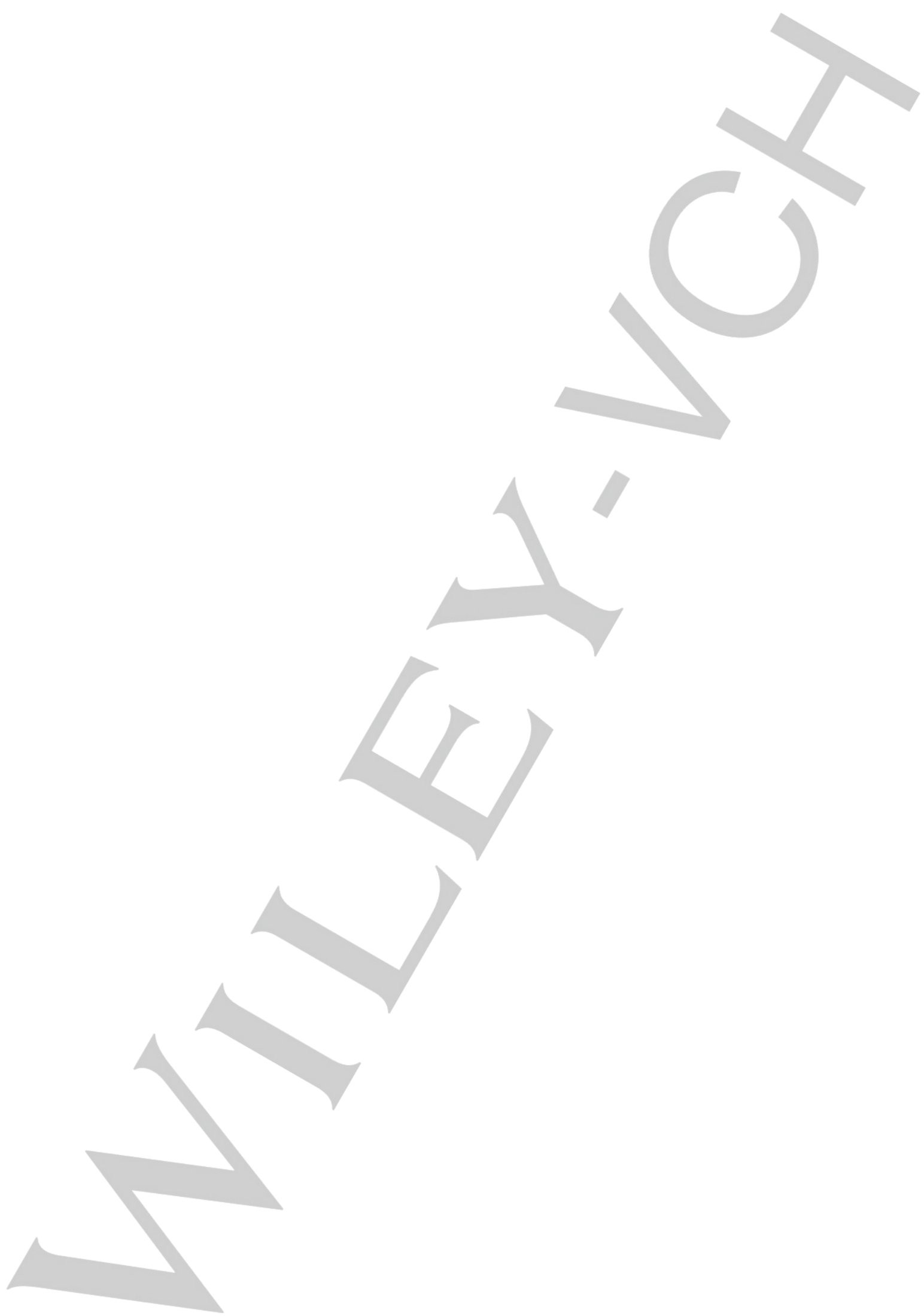